\title{
The Erythemato-Squamous Dermatology Diseases Severity Determination using Self-Organizing Map
}

\author{
Haryanto $^{1}$, Bain Khusnul Khotimah ${ }^{2}$, Miftahul Ulum ${ }^{1}$, Diana Rahmawati ${ }^{1}$, Koko Joni ${ }^{1}$, \\ Ahmad Ubaidillah ${ }^{1}$, Riza Alfita ${ }^{1}$, and Lilik Anifah ${ }^{1}$
}

\begin{abstract}
A new approach based on the implementation of Self Organizing Map is presented for automated detection of erythemato-squamous diseases. The purpose of clustering techniques is in order to determinate the severity of erythematosquamous dermatology diseases. The studied domain contained records of patients with known diagnosis. Self-Organizing Map algorithm's task was to classify the data points, in this case the patients with attribute data, to one of the six clusters (psoriasis, seboreic dermatitis, lichen planus, pityriasis rosea, cronic dermatitis, dan pityriasis rubra pilaris). The algorithm was used to detect the six erythemato-squamous diseases when 33 features defining five disease indications were used. The purpose is to determine an optimum classification scheme for this problem. The present research demonstrated that the features well represent the erythemato-squamous diseases and SOM algorithm's task achieved high classification accuracies. The best accuration for psoriasis 85,94\%, seboreic dermatitis 40,48\%, lichen planus 56,25\%, and pityriasis rosea 82,61\%, with learning rate value were $0,1,0,2,0,9$, and 0,4 .
\end{abstract}

Keywords — Erythemato-squamous, Self-Organizing Map, classification, dermatology.

\section{INTRODUCTION}

$\mathrm{T}$ he differential diagnosis of erythemato-squamous diseases is a real problem in dermatology. They all share the clinical features of erythema and scaling, with very little differences. The diseases in this group are psoriasis, seboreic dermatitis, lichen planus, pityriasis rosea, cronic dermatitis, and pityriasis rubra pilaris. Usually a biopsy is necessary for the diagnosis but unfortunately these diseases share many histopathological features as well [1].

Research about erythemato-squamous diseases has been researched many researcher in the world. Automatic detection of erythemato-squamous diseases using k-means clustering has been investigated by Ubeyli [2]. Classification of erythemato-squamous diseases using Support Vector Machine investigated by Derya [3] and another investigated by Loris [4].

Self-Organizing Map (SOM) invented by Kohonen [5], [6]. SOM network learning some grop pattern and a pattern made into a single cluster that has certain characteristics [7]. SOM procedure is divided into three parts, namely: Normalization, Trainings, and retrieval of information from the training. The goal of normalization is to avoid variable that has value too high against the value of other data. Normalization process variable value seeing a value between 0 and 1 , is expected to be detraining variable is normal with other data. After data normalization, data matrix detraining shaped by a particular procedure, recommended training held at least 500 times. The third step, namely the use trainings results in the form of weights (weight) for each cluster. Weight (weight) obtained is used to test the data that will be tested.

${ }^{1}$ Haryanto, Miftahul Ulum, Diana Rahmawati, Koko Joni, Ahmad Ubaidillah, Riza Alfita, and Lilik Anifah are with Departement of Electrical Engineering, Trunojoyo University Madura, Bangkalan, Indonesia. E-mail: haryanto_utm@yahoo.com;;;;;;.

${ }^{2}$ Bain Khusnul Khotimah are with Departement of Informatics Engineering, Trunojoyo University Madura, Bangkalan, Indonesia.Email: bain_kk@gmail.com.
In this paper we present the application of a selforganizing map to the problem of differential diagnosis of erythemato-squamous diseases, which represents a major issue in dermatology.

This paper is outlined as follows: In section 2 we briefly describe material and the proposed method. Experimental results and discussions will be presented in section 3, followed by discussions in section 4 , conclusions in section 5, and future work in section 6 .

\section{MATERIAL AND METHOD}

\section{A. Material}

We observed 231 erythemato-squamous diseases data obtained from Machine Learning Repository (UCI) dataset [1], included 30 training data and 201 testing data. Training data contain 5 data for psoriasis, 5 data for seboreic dermatitis, 5 data for lichen planus, 5 data for pityriasis rosea, 5 data for cronic dermatitis, and 5 data for pityriasis rubra pilaris.

The dataset constructed for this domain, the family history feature has the value 1 if any of these diseases has been observed in the family, and 0 otherwise. The age feature simply represents the age of the patient. Every other feature (clinical and histopathological) was given a degree in the range of 0 to 3 .

Hardware specification used in this research is Dell Inspiron N3010 with Processor Intel(R) Core(TM) i5 CPU M430@2,27 GHz installed memory (RAM) 2,00 GB.

\section{B. Method}

Method of Self Organizing Map (SOM) has been progressing rapidly both in the substance of the SOM and its application to clustering in various fields. Modular network SOM developed by Kazuhiro Tokunaga and Tetsuo Furukawa [9]. Networks Artificial Counterpropagation developed by Davide Ballabio, Viviana Consonni, and Roberto Todeschini [10]. SOM of SOMs developed by Tetsuo Furukawa [11], Dieter Müller developed a self-organized mapping of clusters of 
data into groups of neurons [12]. Comparision between SOM-based optimization and particle swarm optimization for minimized construction time from a secant pile wall is researched by Jieh-Haur Chen [13]. Still a lot of research about other SOM. Figure of classic SOM configuration is figured in fig 1.

Erythemato-squamous diseases classification in this research using classic SOM. This research is divided into 9 experiments described in Table 1.

The clasters of this research are divided into 6 clasters described in Table 2. Clasters of this research are Psoriasis, Seboreic dermatitis, Lichen planus, Pityriasis rosea, Cronic dermatitis and Pityriasis rubra pilaris.

Algorithm of this research is figured in fig 2. The step of learning using SOM are initialization, determination the number of classes, setting a learning rate parameter, determination of the iteration value, and calculating the distance between random data into each input weight.

The classic SOM network learning algorithm can be formulated as follows [6]:

a. Set learning iteration number $t=0$. Then initialize all weights wij with small random values (or initialize the weights using input data). Set the initial topological neighborhood (d0). Set the initial learning rate $(0)$ and set the total number of iterations (T)

b. While iteration number $(\mathrm{t})$ is less than $\mathrm{T}$, repeat Step 3-Step 6.

c. Choose an input vector $\mathrm{x}$ randomly in the training set.

d. Determine the neuron $\mathrm{j}$ so that its weight vector wj is the closest to the input vector and call it as the winner neuron. The winner neuron $\mathrm{j}$ has the closest distance, $\operatorname{Dmin}(\mathrm{t})$ to the input pattern $\mathrm{x}(\mathrm{t})$, where $\operatorname{Dmin}(\mathrm{t})$ is given:

e. $D_{\min }(t)=\min D_{i}(t)=\min \sum_{j}\left(x_{i j}(t)-w_{i j}(t)\right)^{2}$

f. Update the weight vectors of both the winner neuron $\mathrm{j}$ and its neighbors as:

g. $W_{i}(t+1)=W_{i}(t)+\alpha(t) \bullet\left(x-W_{i}(t)\right)$

$\forall i \in N_{i}$

h. where $\alpha(t)$ is a learning rate function that exponentially decreases with time. Further, we define a neighborhood order function $\mathrm{d}(\mathrm{t})$ which exponentially decreases with time. In this paper, the following equations are used for $\alpha(\mathrm{t})$ and $\mathrm{d}(\mathrm{t})$ :

i. $\alpha(t)=\alpha_{0} e^{-t / 3 T}$

$$
d(t)=\left[d_{0} e^{-t / 3 T}\right]
$$

j. where $[y]$ denotes the largest integer less or equal to $\mathrm{y}$.

$\mathrm{k}$. Set $\mathrm{t}=\mathrm{t}+1$ and if $\mathrm{t}<\mathrm{T}$ go to Step 3, and otherwise STOP.

\section{RESULT AND DISCUSSION}

Difficulty for the differential diagnosis is that a disease may show the features of another disease at the beginning stage and may have the characteristic features at the following stages.

Patients were first evaluated clinically with 12 features. Afterwards, skin samples were taken for the evaluation of 22 histopathological features. The values of the histopathological features are determined by an analysis of the samples under a microscope. The Clinical Attributes areerythema, scaling, definite borders, itching, koebner phenomenon, polygonal papules, follicular papules, oral mucosal involvement, knee and elbow involvement, scalp involvement, family history, and Age. Histopathological Attributes melanin incontinence, eosinophils in the infiltrate, PNL infiltrate, fibrosis of the papillary dermis, exocytosis, acanthosis, hyperkeratosis, parakeratosis, clubbing of the rete ridges, elongation of the rete ridges, thinning of the suprapapillary epidermis, spongiform pustule, munro microabcess, focal hypergranulosis, disappearance of the granular layer, vacuolisation and damage of basal layer, spongiosis, saw-tooth appearance of retes, follicular horn plug, perifollicular parakeratosis, inflammatory monoluclear inflitrate, and band-like infiltrate.

Parameters of learning are described in Table 1 for minimal value, Table 2 for maximal value and Table 3 for average value. Table 3 , 4, and 5 shows that the some parameters had the overlap value among clasters and it is not linear. That is why we try to overcome to classify automatically using SOM.

Accuracy of each group is shown in fig 4 , fig 5 , fig 6 , fig 7 , fig 8 , and fig 9 . Fig 4 is figured the accuray of the fisrt group (Psoriasis), fig 5 is figured the accuray of the second group (Seboreic dermatitis), fig 6 is figured the accuray of the second group (Lichen planus dermatitis), fig 7 is figured the accuray of the second group (Pityriasis rosea), fig 8 is figured the accuray of the second group ( Cronic dermatitis) and fig 9 is figured the accuray of the second group ( Pityriasis rubra pilaris).

Fig 4 shows that the accuracy of cluster 1 (Psoriasis group), first experiment and second experiment are 85,9375\%. Thirth, fourth, and fifth experiment have accuracy 84,375 \% but sixth, seventh, eighth and ninth experiment give accuracy $0 \%$.

Fig 5 shows that the accuracy of second cluster (Seboreic dermatitis group), first experiment and second experiment are $40,476 \%$, thirth has accuracy $0 \%$, fourth and sixth $21,428 \%$, fifth 40,476 , seventh and ninth have accuracy $35,714 \%$, and eighth experiment has accuracy 38,095\%.

Fig 6 shows that the accuracy of thirth cluster (Lichen planus group), first and second experiment are 31,25\%, thirth has accuracy 18,75\%, fourth, fifth and sixth $12,5 \%$, seventh $0 \%$, eighth has accuracy $18,75 \%$ and ninth experiment has accuracy 56,25\%.

Fig 7 shows that the accuracy of fourth cluster (Pityriasis rosea group), first experiment and second experiment are $78,26 \%$. Thirth is $69,565 \%$, fourth has accuracy $82,61 \%$,fifth experiment has accuracy 4,34\%, sixth has accuracy $60,869 \%$, eighth has $17,39 \%$ but seventh and ninth $0 \%$.

Fig 8 shows that the accuracy of fifth cluster (Cronic dermatitis group), first experiment and second experiment are $86,49 \%$. Thirth is $43,24 \%$, fourth has accuracy $35,13 \%$, fifth experiment has accuracy $13,51 \%$, sixth has accuracy $37,84 \%$, seventh and eighth have $48,65 \%$ but ninth has accuracy $10,81 \%$.

Fig 9 shows that the accuracy of sixth cluster (Pityriasis rubra pilaris group), first, second, thirth, fourth, and seventh experiment 93,33\%, fifth has accuracy $7,14 \%$, sixth experiment has accuracy $6,67 \%$, eighth has accuracy $100 \%$, and ninth has accuracy $0 \%$.

Time needs to process of each experiment is described in Table 7. First, seventh, eighth, and ninth experiment 
need 0,2028 second to process. Second and fourth experiment need 0,187 second, thirth experiment needs 0,218 second, fifth and sixth experiments consume 0,265 and 0,234 second. Graph of time-consuming for each experiment is figured in fig 10.

\section{CONCLUSION}

In this research, we proposed an effective Erythematosquamous diseases classification system without the need for user interaction. Experimental results have been provided to show the successful of the system that could help medical doctors as decision support system to determine the claster of erythemato-squamous diseases.

\section{A. Future Work}

The system could classify the six claster (Psoriasis, Seboreic dermatitis, Lichen planus, Pityriasis rosea, Cronic dermatitis and Pityriasis rubra pilaris), the future work we develop the more effective and robust classification machine.

\section{ACKNOWLEDGEMENT}

This research was supported by UC Irvine Machine Learning Repository (UCI).

\section{REFERENCES}

[1]. http://archive.ics.uci.edu/ml/

[2]. Ubeyli, Elif Derya and Erdoğan Doğdu 2008, Automatic detection of erythemato-squamous diseases using k-means clustering has been investigated Journal of Mecidal System

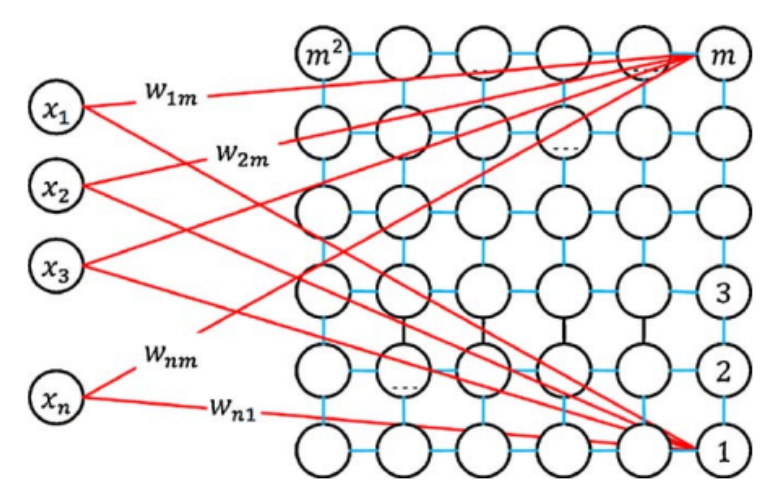

Figure 1. Configuration of SOM

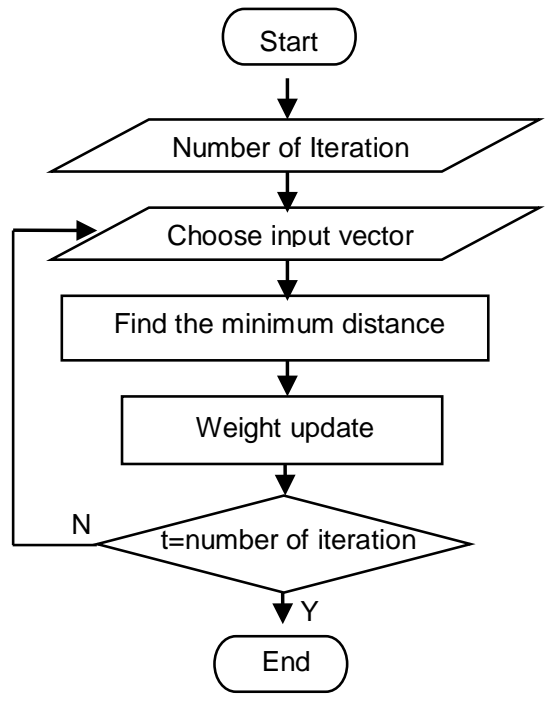

Figure 2. Algorithm of classic SOM
Volume 34, Number 2, 179-184, DOI: 10.1007/s10916-0089229-6

[3]. Kohonen, T., 1982. Self-organized formation of topologically correct feature maps. Biological Cybernetics 43, 59e69.

[4]. Kohonen, T., 1982. Analysis of a simple self-organizing process Biological Cybernetics 44, 135e140.

[5]. Kohonen, T., 2001. Self-Organizing Maps. Springer-Verlag, Berlin.

[6]. A.M. Kalteh, 2008, Review of the self-organizing map (SOM) approach in water resources: Analysis, modelling and application, Environmental Modelling \& Software 23 (2008) 835e845, Science Direct Elsevier.

[7]. Haykin, S., 1999, Neural Networks: A Comprehensive Foundation, Prentice Hall Upper Saddle River, New Jersey.

[8]. Vesanto, J., Alhoniemi, E., 2000, Clustering of the self organizing map. IEEE, Transactions on Neural Networks 11 (3), 586e600. Woolf AD, Pfleger B. "Burden of major musculoskeletal conditions", Bull World Health Organ 2003;81:646-656.

[9]. Kazuhiro Tokunaga, Tetsuo Furukawa, Modular network SOM, Neural Networks 22 (2009) 82-90, Science Direct Elsevier, 2009.

[10]. Davide Ballabio, Viviana Consonni, Roberto Todeschini, The Kohonen and CP-ANN toolbox: A collection of MATLAB modules for Self Organizing Maps and Counterpropagation Artificial Neural Networks, Chemometrics and Intelligent Laboratory Systems xxx (2009) xxx-xxx, Science Direct Elsevier, 2009.

[11]. Tetsuo Furukawa, SOM of SOMs, Neural Networks 22 (2009) 463§478, Science Direct Elsevier, 2009.

[12]. Dieter Müller, Self organized mapping of data clusters to neuron groups, Neural Networks 22 (2009) 415-424, Science Direct Elsevier, 2009.

[13]. Jieh-Haur Chen, Comparison of SOM-based optimization and particle swarm optimization for minimizing the construction time of a secant pile wall, Automation in Construction 18 (2009) 844-848, Science Direct Elsevier, 2009.

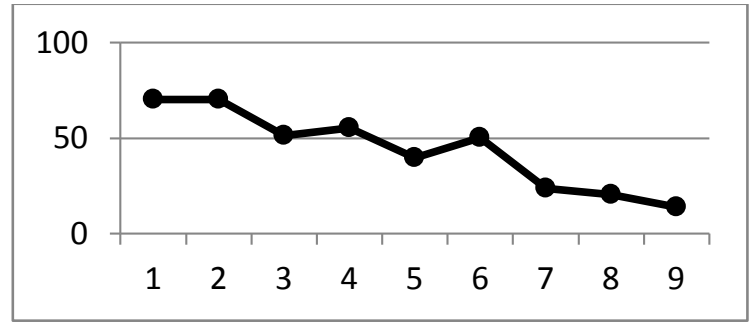

Figure 3. System accuracy using learning rate value 0,1 to 0,9

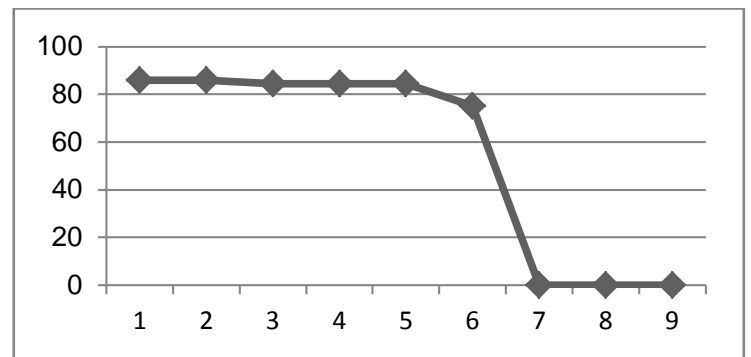

Figure 4. System accuracy using learning rate value 0,1 to 0,9 of cluster 1 (Psoriasis group)

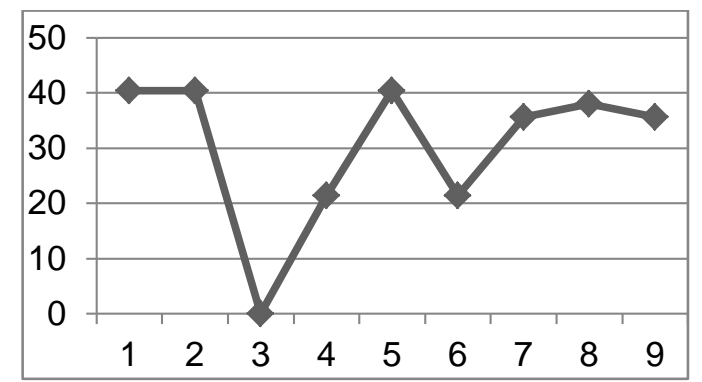

Figure 5. System accuracy using learning rate value 0,1 to 0,9 of cluster 2 (Seboreic dermatitis group) 


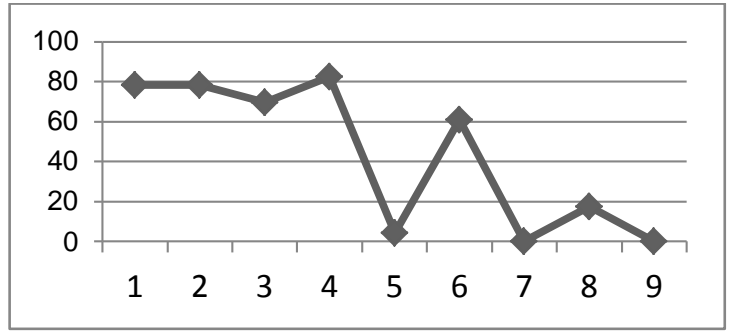

Figure 7. System accuracy using learning rate value 0,1 to 0,9 of cluster 4 (Pityriasis rosea group)

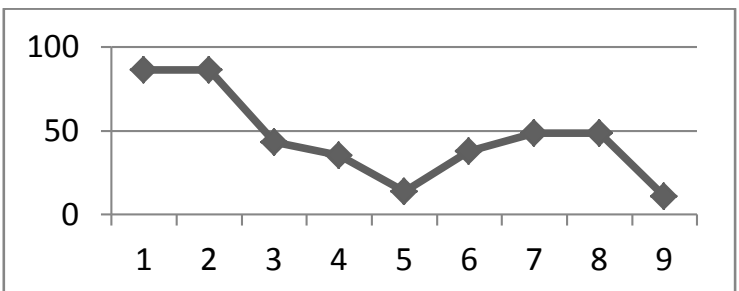

Figure 8. System accuracy using learning rate value 0,1 to 0,9 of cluster 5 (Cronic dermatitis group)

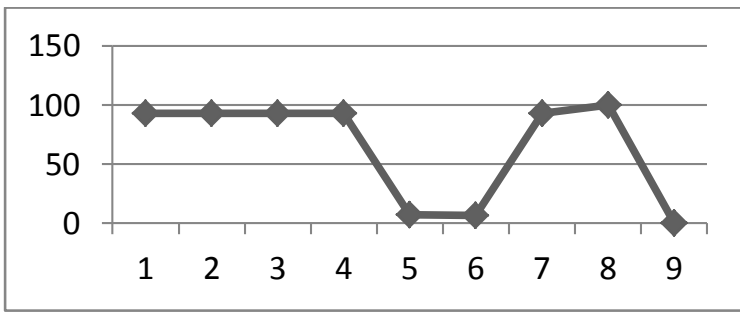

Figure 9. System accuracy using learning rate value 0,1 to 0,9 of cluster 6 (Pityriasis rubra pilaris group)

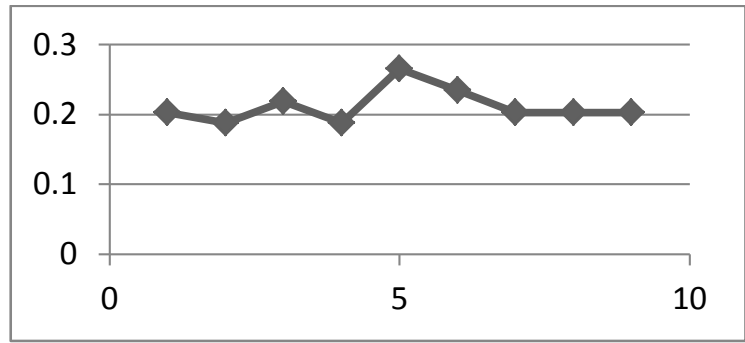

Figure 10. Time-consuming for each experiment

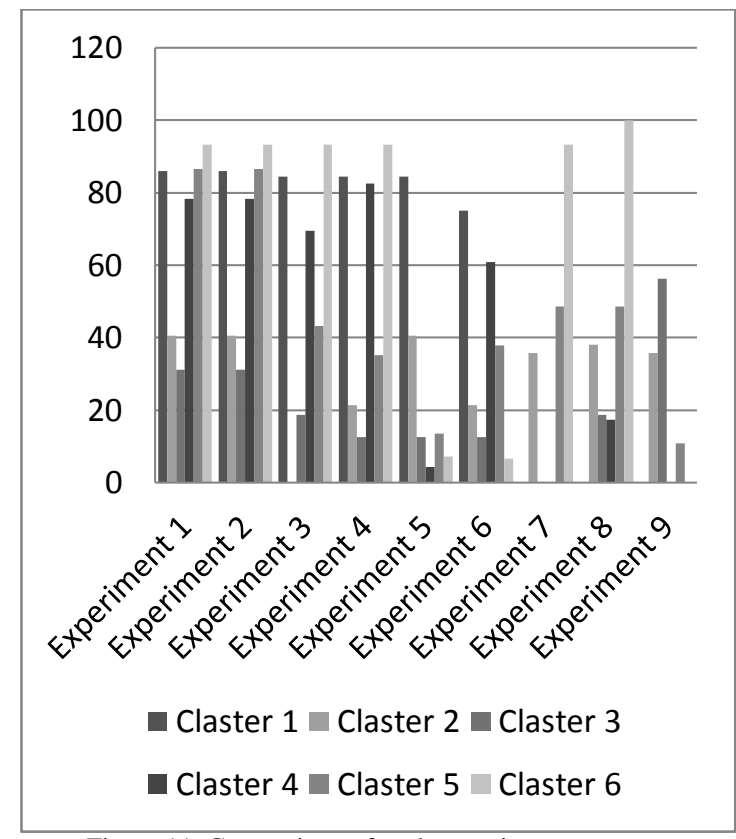

Figure 11. Comparison of each experiment accuracy

TABLE 1.

EXPERIMENTS OF THE RESEARCH

\begin{tabular}{cccc}
\hline \hline \multicolumn{4}{c}{ ExPERIMENTS OF THE RESEARCH } \\
\hline No & Experiment & $\begin{array}{c}\text { Learning } \\
\text { rate }\end{array}$ & Iteration \\
\hline 1 & Experiment 1 & 0,1 & 500 \\
2 & Experiment 2 & 0,2 & 500 \\
3 & Experiment 3 & 0,3 & 500 \\
4 & Experiment 4 & 0,4 & 500 \\
5 & Experiment 5 & 0,5 & 500 \\
6 & Experiment 6 & 0,6 & 500 \\
7 & Experiment 7 & 0,7 & 500 \\
8 & Experiment 8 & 0,8 & 500 \\
9 & Experiment 9 & 0,9 & 500 \\
\hline \hline
\end{tabular}

TABLE 2.

CLASTER OF THE RESEARCH

\begin{tabular}{ccc}
\hline \hline No & Claster & Group \\
\hline 1 & Claster 1 & Psoriasis \\
2 & Claster 2 & Seboreic Dermatitis \\
3 & Claster 3 & Lichen Planus \\
4 & Claster 4 & Pitriasis Rosea \\
5 & Claster 5 & Cronic Dermatitits \\
6 & Claster 6 & Pityriasis Rubra Pilaris \\
\hline \hline
\end{tabular}


TABLE 3.

MINIMAL VALUE OF LEARNING PARAMETERS

\begin{tabular}{|c|c|c|c|c|c|c|}
\hline Parameter & 1 & 2 & 3 & 4 & 5 & 6 \\
\hline 1: Erythema & 0 & 1 & 0 & 1 & 0 & 1 \\
\hline 2: Scaling & 1 & 1 & 0 & 1 & 0 & 1 \\
\hline 3: Definite borders & 1 & 0 & 0 & 0 & 0 & 0 \\
\hline 4: Itching & 0 & 0 & 0 & 0 & 0 & 0 \\
\hline 5: Koebner phenomenon & 0 & 0 & 0 & 0 & 0 & 0 \\
\hline 6: Polygonal papules & 0 & 0 & 0 & 0 & 0 & 0 \\
\hline 7: Follicular papules & 0 & 0 & 0 & 0 & 0 & 1 \\
\hline 8: Oral mucosal involvement & 0 & 0 & 0 & 0 & 0 & 0 \\
\hline 9: Knee and elbow involvement & 0 & 0 & 0 & 0 & 0 & 0 \\
\hline 10: Scalp involvement & 0 & 0 & 0 & 0 & 0 & 0 \\
\hline 11: Family history, (0 or 1 ) & 0 & 0 & 0 & 0 & 0 & 0 \\
\hline 12: Melanin incontinence & 0 & 0 & 0 & 0 & 0 & 0 \\
\hline 13: Eosinophils in the infiltrate & 0 & 0 & 0 & 0 & 0 & 0 \\
\hline 14: PNL infiltrate & 0 & 0 & 0 & 0 & 0 & 0 \\
\hline $\begin{array}{l}\text { 15: Fibrosis of the papillary } \\
\text { dermis }\end{array}$ & 0 & 0 & 0 & 0 & 1 & 0 \\
\hline 16: Exocytosis & 0 & 0 & 0 & 0 & 0 & 0 \\
\hline 17: Acanthosis & 0 & 0 & 0 & 0 & 1 & 1 \\
\hline 18: Hyperkeratosis & 0 & 0 & 0 & 0 & 0 & 0 \\
\hline 19: Parakeratosis & 0 & 0 & 0 & 0 & 0 & 0 \\
\hline 20: Clubbing of the ridges & 0 & 0 & 0 & 0 & 0 & 0 \\
\hline 21: Elongation of the rete ridges & 1 & 0 & 0 & 0 & 0 & 0 \\
\hline \multicolumn{7}{|l|}{ 22: Thinning of the suprapaillary } \\
\hline Epidermis & 0 & 0 & 0 & 0 & 0 & 0 \\
\hline 23: Spongiformpustule & 0 & 0 & 0 & 0 & 0 & 0 \\
\hline 24: Munro microabcess & 0 & 0 & 0 & 0 & 0 & 0 \\
\hline 25: Focal hypergranulosis & 0 & 0 & 0 & 0 & 0 & 0 \\
\hline \multicolumn{7}{|l|}{ 26: Disappearance of the granular } \\
\hline Layer & 0 & 0 & 0 & 0 & 0 & 0 \\
\hline \multicolumn{7}{|l|}{ 27: Vacuolisation and damage of } \\
\hline Basal layer & 0 & 0 & 0 & 0 & 0 & 0 \\
\hline 28: Spongiosis & 0 & 0 & 0 & 0 & 0 & 0 \\
\hline 29: Saw-tooth appearance of retes & 0 & 0 & 0 & 0 & 0 & 0 \\
\hline 30: Follicular horn plug & 0 & 0 & 0 & 0 & 0 & 0 \\
\hline 31: Perifollicular parakeratos is & 0 & 0 & 0 & 1 & 0 & 1 \\
\hline \multicolumn{7}{|l|}{ 32: Inflammatory monoluclear } \\
\hline Infiltrate & 0 & 0 & 0 & 0 & 0 & 0 \\
\hline 33: Band-like infiltrate & 0 & 0 & 0 & 0 & 0 & 0 \\
\hline 34: Age (linear) & 8 & 10 & 16 & 12 & 8 & 7 \\
\hline
\end{tabular}

TABLE 4.

MAXIMAL VALUE OF LEARNING PARAMETERS

\begin{tabular}{|c|c|c|c|c|c|c|}
\hline Parameter & 1 & 2 & 3 & 4 & 5 & 6 \\
\hline 1: Erythema & 3 & 3 & 3 & 3 & 3 & 3 \\
\hline 2: Scaling & 3 & 3 & 3 & 2 & 3 & 2 \\
\hline 3: Definite borders & 3 & 2 & 3 & 2 & 3 & 2 \\
\hline 4: Itching & 3 & 3 & 3 & 3 & 3 & 2 \\
\hline 5: Koebner phenomenon & 3 & 2 & 3 & 3 & 0 & 0 \\
\hline 6: Polygonal papules & 0 & 0 & 3 & 0 & 0 & 0 \\
\hline 7: Follicular papules & 2 & 1 & 0 & 0 & 2 & 3 \\
\hline 8: Oral mucosal involvement & 0 & 2 & 3 & 0 & 0 & 0 \\
\hline 9: Knee and elbow involvement & 3 & 1 & 2 & 0 & 1 & 3 \\
\hline 10: Scalp involvement & 3 & 0 & 1 & 0 & 0 & 2 \\
\hline 11: Family history, ( 0 or 1 ) & 1 & 1 & 0 & 0 & 0 & 1 \\
\hline 12: Melanin incontinence & 0 & 0 & 3 & 0 & 0 & 0 \\
\hline 13: Eosinophils in the infiltrate & 2 & 2 & 2 & 1 & 1 & 0 \\
\hline 14: PNL infiltrate & 3 & 3 & 0 & 1 & 0 & 1 \\
\hline 15: Fibrosis of the papillary dermis & 0 & 0 & 2 & 0 & 3 & 0 \\
\hline 16: Exocytosis & 2 & 3 & 3 & 3 & 2 & 3 \\
\hline 17: Acanthosis & 3 & 3 & 3 & 2 & 3 & 2 \\
\hline 18: Hyperkeratosis & 3 & 3 & 2 & 2 & 2 & 2 \\
\hline 19: Parakeratosis & 3 & 3 & 3 & 2 & 2 & 2 \\
\hline 20: Clubbing of the ridges & 3 & 0 & 0 & 0 & 0 & 1 \\
\hline 21: Elongation of the rete ridges & 3 & 2 & 0 & 0 & 3 & 1 \\
\hline \multicolumn{7}{|l|}{ 22: Thinning of the suprapaillary } \\
\hline Epidermis & 3 & 1 & 0 & 0 & 1 & 0 \\
\hline 23: Spongiformpustule & 3 & 2 & 0 & 0 & 0 & 1 \\
\hline 24: Munro microabcess & 3 & 0 & 3 & 1 & 0 & 0 \\
\hline 25: Focal hypergranulosis & 0 & 0 & 3 & 0 & 0 & 1 \\
\hline \multicolumn{7}{|l|}{ 26: Disappearance of the granular } \\
\hline Layer & 3 & 0 & 2 & 2 & 0 & 0 \\
\hline \multicolumn{7}{|l|}{ 27: Vacuolisation and damage of } \\
\hline Basal layer & 1 & 0 & 3 & 0 & 0 & 0 \\
\hline 28: Spongiosis & 0 & 3 & 3 & 3 & 2 & 3 \\
\hline 29: Saw-tooth appearance of retes & 0 & 0 & 3 & 1 & 0 & 0 \\
\hline 30: Follicular horn plug & 0 & 1 & 1 & 0 & 1 & 3 \\
\hline 31: Perifollicular parakeratos is & 0 & 1 & 0 & 0 & 0 & 3 \\
\hline \multicolumn{7}{|l|}{ 32: Inflammatory monoluclear } \\
\hline Infiltrate & 3 & 3 & 3 & 3 & 3 & 3 \\
\hline 33: Band-like infiltrate & 1 & 2 & 3 & 0 & 1 & 1 \\
\hline 34: Age (linear) & 75 & 75 & 75 & 75 & 75 & 75 \\
\hline
\end{tabular}


TABLE 5.

AVERAGE VALUE OF LEARNING PARAMETERS

\begin{tabular}{|c|c|c|c|c|c|c|}
\hline Parameter & 1 & 2 & 3 & 4 & 5 & 6 \\
\hline 1: Erythema & 3 & 3 & 3 & 3 & 3 & 3 \\
\hline 2: Scaling & 3 & 3 & 3 & 2 & 3 & 2 \\
\hline 3: Definite borders & 3 & 2 & 3 & 3 & 3 & 2 \\
\hline 4: Itching & 3 & 3 & 3 & 3 & 3 & 2 \\
\hline 5: Koebner phenomenon & 3 & 2 & 3 & 3 & 1 & 0 \\
\hline 6: Polygonal papules & 0 & 0 & 3 & 3 & 0 & 0 \\
\hline 7: Follicular papules & 2 & 1 & 0 & 0 & 2 & 3 \\
\hline 8: Oral mucosal involvement & 0 & 0 & 3 & 2 & 0 & 0 \\
\hline 9: Knee and elbow involvement & 3 & 3 & 2 & 0 & 1 & 3 \\
\hline 10: Scalp involvement & 3 & 3 & 1 & 0 & 0 & 2 \\
\hline 11: Family history, (0 or 1 ) & 1 & 1 & 0 & 0 & 0 & 1 \\
\hline 12: Melanin incontinence & 0 & 0 & 3 & 2 & 0 & 0 \\
\hline 13: Eosinophils in the infiltrate & 2 & 2 & 2 & 1 & 1 & 0 \\
\hline 14: PNL infiltrate & 3 & 3 & 1 & 1 & 0 & 1 \\
\hline $\begin{array}{l}\text { 15: Fibrosis of the papillary } \\
\text { dermis }\end{array}$ & 0 & 0 & 2 & 0 & 3 & 3 \\
\hline 16: Exocytosis & 2 & 3 & 3 & 3 & 2 & 3 \\
\hline 17: Acanthosis & 3 & 3 & 3 & 2 & 3 & 3 \\
\hline 18: Hyperkeratosis & 3 & 3 & 2 & 2 & 2 & 2 \\
\hline 19: Parakeratosis & 3 & 3 & 3 & 2 & 2 & 2 \\
\hline 20: Clubbing of the ridges & 3 & 3 & 0 & 0 & 0 & 1 \\
\hline 21: Elongation of the rete ridges & 3 & 2 & 0 & 0 & 3 & 2 \\
\hline \multicolumn{7}{|l|}{ 22: Thinning of the suprapaillary } \\
\hline Epidermis & 3 & 3 & 0 & 0 & 1 & 0 \\
\hline 23: Spongiformpustule & 3 & 2 & 0 & 0 & 0 & 1 \\
\hline 24: Munro microabcess & 3 & 2 & 3 & 1 & 0 & 0 \\
\hline 25: Focal hypergranulosis & 0 & 0 & 3 & 3 & 0 & 1 \\
\hline \multicolumn{7}{|l|}{ 26: Disappearance of the granular } \\
\hline Layer & 3 & 2 & 2 & 2 & 0 & 0 \\
\hline \multicolumn{7}{|l|}{ 27: Vacuolisation and damage of } \\
\hline Basal layer & 1 & 0 & 3 & 2 & 0 & 0 \\
\hline 28: Spongiosis & 0 & 3 & 3 & 3 & 2 & 3 \\
\hline 29: Saw-tooth appearance of retes & 0 & 0 & 3 & 1 & 0 & 0 \\
\hline 30: Follicular horn plug & 0 & 1 & 1 & 0 & 1 & 3 \\
\hline 31: Perifollicular parakeratos is & 0 & 1 & 0 & 0 & 0 & 3 \\
\hline \multicolumn{7}{|l|}{ 32: Inflammatory monoluclear } \\
\hline Infiltrate & 3 & 3 & 3 & 3 & 3 & 3 \\
\hline \multirow[t]{2}{*}{ 33: Band-like infiltrate } & 2 & 2 & 3 & 3 & 1 & 1 \\
\hline & 7 & 7 & 6 & 7 & 7 & 5 \\
\hline 34: Age (linear) & 5 & 0 & 5 & 0 & 0 & 6 \\
\hline
\end{tabular}

TABLE 6.

ACCURACY OF WHOLE SYSTEM

\begin{tabular}{ccc}
\hline \hline No & Experiment & Accuracy (\%) \\
\hline 1 & Experiment 1 (with learning rate 0,1) & 70,149 \\
2 & Experiment 2 (with learning rate 0,1) & 70,149 \\
3 & Experiment 3 (with learning rate 0,1) & 51,243 \\
4 & Experiment 4 (with learning rate 0,1) & 55,223 \\
5 & Experiment 5 (with learning rate 0,1) & 39,800 \\
6 & Experiment 6 (with learning rate 0,1) & 50,248 \\
7 & Experiment 7 (with learning rate 0,1) & 23,880 \\
8 & Experiment 8 (with learning rate 0,1) & 20,398 \\
9 & Experiment 9 (with learning rate 0,1) & 13,930 \\
\hline \hline
\end{tabular}

TABLE 7.

TIME-CONSUMING FOR EACH EXPERIMENT

\begin{tabular}{cc}
\hline Learning Rate & Time (Second) \\
\hline Experiment 1 (learning Rate 0,1) & 0,2028013 \\
Experiment 2 (learning Rate 0,2) & 0,1872012 \\
Experiment 3 (learning Rate 0,3) & 0,2184014 \\
Experiment 4 (learning Rate 0,4) & 0,1872012 \\
Experiment 5 (learning Rate 0,5) & 0,2652017 \\
Experiment 6 (learning Rate 0,6) & 0,2348015 \\
Experiment 7 (learning Rate 0,7) & 0,2028013 \\
Experiment 8 (learning Rate 0,8) & 0,2028013 \\
Experiment 9 (learning Rate 0,9) & 0,2028013 \\
\hline \hline
\end{tabular}

